\title{
ANALYSIS OF THE SKOLITHOS ICHNOFACIES FROM THE CAMBRIAN MONTALTO QUARTZITE MEMBER OF THE HARPERS FORMATION IN SOUTH CENTRAL PENNSYLVANIA
}

\author{
GOURLEY, Jonathan R.; KEY*, Marcus M., Jr., Dept. of Geology, P.O. Box 1773, \\ Dickinson College, Carlisle, PA 17013-2896, U.S.A.
}

The Lower Cambrian Chilhowee Group outcrops in the South Mountain anticlinorium of south central Pennsylvania. The depositional environments of these metasedimentary strata have been difficult to interpret due to low grade metamorphism that they experienced during the Alleghanian Orogeny. An ichnofacies analysis was performed on the Skolithos piperock unit of the Montalto Quartzite Member of the Harpers Formation. The goal was to independently test the hypothesized depositional environment provided by the physical sedimentologic data. The Skolithos piperock unit of the Montalto is a white, fine to medium grained $(0.075$ to $0.75 \mathrm{~mm})$, laminated to thick-bedded, vitreous quartzite that contains abundant Skolithos tubes. This unit of the Montalto is exceptionally well exposed at an outcrop knob known as Pole Steeple, above Laurel Lake in Michaux State Forest in Cumberland County, Pennsylvania.

Skolithos tubes were identified on exposed bedding planes and were plotted on 12 $400 \mathrm{~cm}^{2}$ quadrats. A total of 1,269 tubes was measured. Due to the potential structural deformation of the Skolithos piperock unit during folding, the Skolithos tubes were examined for strain. Skolithos tubes typically have circular cross sections, but those at Pole Steeple qualitatively appeared deformed. The long and short diameters of 10 randomly selected tubes per quadrat were measured. The long diameters ( $m e a n=$ $6.26 \mathrm{~mm}$ ) ranged from 37 to $58 \%$ longer (mean $=48 \%$ ) than the short diameters (mean $=4.24 \mathrm{~mm}$ ). To determine if the tubes were consistently deformed in one direction, the orientation of the deformed tubes was measured. All but one of the quadrats had a random orientation of long axes. Thus, no "un-deformation" transformation was applied to the tubes' distributions.

Tube densities, nearest neighbor distances, and $\mathrm{R}$ values (a spatial distribution clustering metric) were calculated for each quadrat. Tube densities per quadrat ranged from 2,154 to 4,254 tubes $/ \mathrm{m}^{2}$ (mean $=2,812$ tubes $\left./ \mathrm{m}^{2}\right)$. The mean nearest neighbor distances per quadrat ranged from 11.3 to $13.4 \mathrm{~mm}($ mean $=12.1 \mathrm{~mm})$. R values per quadrat ranged from 1.22 to 1.34 (mean $=1.27)$. All $\mathrm{R}$ values were significantly different from a random distribution $(\mathrm{P}<0.05)$. The $\mathrm{R}$ values indicate a more uniform dispersion suggesting negative interaction among the tube building organisms possibly resulting from competition for food or space.

Published ranges of Skolithos tube densities and $\mathrm{R}$ values from Paleozoic strata are very similar to those from this study. The paleoenvironments of these strata have been interpreted as nearshore, high energy, intertidal settings. This is supported in the Skolithos piperock unit of the Montalto by the absence of funnel-topped Monocraterion tubes as well as physical sedimentologic data. 